\title{
Integrated Supply Chain Model for Perishable Items with Trade Credit Policy under Imprecise Environment
}

\author{
Chaman Singh \\ Assistant Professor, Dept. of Mathematics, A.N.D. \\ College (University of Delhi), Delhi-110019
}

\author{
S. R. Singh \\ Reader, Dept. of Mathematics, D.N.(P.G.) College, \\ Meerut, U.P. - 250002
}

\begin{abstract}
It is the purpose of this paper to investigate the integrated cost minimizing strategy with supplier's trade credits offer under fuzzy environment. Supplier permits the retailer a certain fixed period to settle the amount owed to him for the items supplied. Expressions for average integrated inventory cost in fuzzy sense are derived Signed Distance Method is used to defuzzified total fuzzy cost and its optimization with respect to the decision variable is carried out. A numerical example is cited to illustrate the model. A comparison is made between integrated cost policy and the individual cost polices. It is shown that integrated cost policy results in impressive cost reduction. Computer software Mathematics 7.0 is used to derive the optimal policies.
\end{abstract}

Keywords: Supply chain management, Permissible delay, Signed Distance Method

\section{INTRODUCTION}

Increasing competitions in today's global market and the heightened expectations of customers have forced suppliers to offer their customers some grace period to settle the account. Supplier's charges no interest if the outstanding amount is settled within the credit period. However if the account is not settled by the end of the permissible period, interest is charged on the outstanding amount. This arrangement make economic sense for the retailer as he may delay the payment till the end of the permissible delay period, can sell the items and continue to accumulate revenue and earn interest. Goyal (1985) derived an EPQ model under the conditions of permissible delay in payments. Hwang and Shinn (1997) determine the Retailer's pricing and lot sizing policy for exponentially deteriorating product under condition of permissible delay in payments. Chang et al. (2003) determines an EOQ model for deteriorating items under supplier credits linked to ordering quantity. Singh et al. (2007) discussed a perishable inventory model with quadratic demand, partial backlogging and permissible delay in payments.

Integration approach to supply chain has been studied for years. Models for the coordination of supply and manufacturing as well as manufacturing and distribution are reviewed by Thomas and Griffin (1996). Maloni and Benton (1997) review opportunities for operations research models in supply chain partnerships. Yang and Wee (2000) developed an integrated economic ordering policy of deteriorating items for a vendor and a buyer. Aviv (2001) discuss the effect of collaborative forecasting on supply chain management. Wu and Choi (2005) assumed Supplier-supplier relationships in the buyer-supplier triad. Chen and Kang (2007) well thoughtout integrated vendor-buyer cooperative inventory models with variant permissible delay in payments. Rau and Ouyang (2008) have introduced an optimal batch size for integrated production-inventory policy in a supply chain. Kim and Park (2008) have assumed development of a three-echelon SC model to optimize coordination costs. Singh and Singh (2010) developed two echelon supply chain model with imperfect production for weibull distribution deteriorating items.

In classical inventory, models are developed on the basis of that all the parameters in total cost function are fixed and have the certain values. But in day-by-day changing market scenario there may be increase or decrease within a range of the values of the parameters. To deal with such type of irregularities, these parameters are considered as fuzzy in nature. When some parameters are fuzzy in nature, the resultant objective function also becomes fuzzy. Yao and Lee (1999) discussed fuzzy inventory with or without backorder for fuzzy order quantity with trapezoidal fuzzy number. Yao et al. (2000) proposed the fuzzy inventory without backorder for fuzzy order quantity and fuzzy total demand quantity based on the triangular fuzzy numbers. Chang et al. (2004) considered the fuzzy problems for the mixture inventory model involving variable lead - time with backorders and lost sales. Singh and Singh (2008) developed fuzzy inventory model defuzzified by signed distance method. Singh and Singh (2010) developed a supply chain model with imprecise partial backlogging and fuzzy ramp-Type demand.

Most of the above cited references only study the retailer's EOQ model, and pay less attention to supplier's optimal credit time. This paper combines all the above cited situations and develops an integrated cost model with permissible delay in payments for perishable items under fuzzy environment.

\section{METHODOLOGY}

In this paper, we use the concepts of fuzzy set to developing model by fuzzifing the carrying cost, and rate of interest paid/earned by the Interval-Valued Fuzzy Numbers. Signed Distance Method is used to defuzzify the total cost function. We introduce the methodologies as below.

\subsection{Signed Distance Method}

Let $\tilde{A}=[(a, b, c: \lambda),(p, b, q: 1)] \in F(\lambda), 0<\lambda \leq 1 \quad$ be $\quad$ the interval-valued fuzzy number and $\mathrm{A}(\alpha)$ be the, $0 \leq \alpha \leq 1, \alpha$ cut of $\tilde{A}$. We define the Signed Distance of $\tilde{A}$ measured from 0 as 


$$
\begin{aligned}
& d(\tilde{A}, \tilde{0})=\frac{1}{\lambda} \int_{0}^{\lambda} d\left(\left[A_{l}^{U}(\alpha), A_{l}^{L}(\alpha) ; \alpha\right]\right. \\
& \left.U\left[A_{r}^{L}(\alpha), A_{r}^{U}(\alpha) ; \alpha\right], \tilde{0}\right) d \alpha+\frac{1}{1-\lambda} \\
& \int_{\lambda}^{1} d\left(\left[A_{r}^{U}(\alpha), A_{r}^{L}(\alpha) ; \alpha\right], \tilde{0}\right) d \alpha \\
& d(\tilde{A}, \tilde{0})=\frac{1}{8}[6 b+a+c+4 p+4 q \\
& +3(2 b-p-q) \lambda]
\end{aligned}
$$

\subsection{The fuzzy arithmetical operations}

Fuzzy arithmetical operations under Function Principle are as follows.

Suppose $\tilde{A}=\left(a_{1}, a_{2}, a_{3}, a_{4}\right)$ and $\tilde{B}=\left(b_{1}, b_{2}, b_{3}, b_{4}\right)$ are two trapezoidal fuzzy numbers. Then

(1) The addition of $\tilde{A}$ and $\tilde{B}$ is $\tilde{A} \oplus \tilde{B}=\left(a_{1}+b_{1}, a_{2}+b_{2}, a_{3}+b_{3}, a_{4}+b_{4}\right)$, where $a_{1}, a_{2}, a_{3}, a_{4}, b_{1}, b_{2}, b_{3}$ and $b_{4}$ are any real numbers.

(2) The multiplication of $\tilde{A}$ and $\tilde{B}$ is

$\tilde{A} \otimes \tilde{B}=\left(c_{1}, c_{2}, c_{3}, c_{4}\right)$,

Where $T_{1}=\left\{a_{1} b_{1}, a_{1} b_{4}, a_{4} b_{1}, a_{4} b_{4}\right\}$,

$T_{2}=\left\{a_{2} b_{2}, a_{2} b_{3}, a_{3} b_{2}, a_{3} b_{3}\right\}$,

$c_{1}=\min T_{1}, c_{2}=\min T_{2}$

$c_{3}=\max T_{1}, c_{4}=\max T_{2} . \quad$ If $\quad a_{1}, a_{2}$,

$a_{3}, a_{4}, b_{1}, b_{2}, b_{3}$ and $b_{4}$ are all nonzero real

numbers, then $\tilde{A} \otimes \tilde{B}=\left(a_{1} b_{1}, a_{2} b_{2}, a_{3} b_{3}, a_{4} b_{4}\right)$.

(3) If $-\tilde{B}=\left(-b_{4},-b_{3},-b_{2},-b_{1}\right)$, then subtraction of $\tilde{A}$ and $\tilde{B}$ is

$A \Theta B=\left(a_{1}-b_{4}, a_{2}-b_{3}, a_{3}-b_{2}, a_{4}-b_{1}\right)$,

Where $a_{1}, a_{2}, a_{3}, a_{4}, b_{1}, b_{2}, b_{3}$ and $b_{4}$ are any real numbers?

(4) If $1 / \tilde{B}=B^{-1}=\left(1 / b_{4}, 1 / b_{3}, 1 / b_{2}, 1 / b_{1}\right)$,

Where $b_{1}, b_{2}, b_{3}$ and $b_{4}$ are all positive real numbers?

If $a_{1}, a_{2}, a_{3}, a_{4}, b_{1}, b_{2}, b_{3}$ and $b_{4}$ are all nonzero positive real numbers, then the division of $\tilde{A}$ and $\tilde{B}$ is $\tilde{A} \varnothing \tilde{B}=\left(a_{1} / b_{4}, a_{2} / b_{3}, a_{3} / b_{2}, a_{4} / b_{1}\right)$.

(5) Let $\alpha \in \mathrm{R}$, then (i) $\alpha \geq 0, \alpha \otimes \tilde{A}=\left(\alpha a_{1}, \alpha a_{2}, \alpha a_{3}, \alpha a_{4}\right)$,

(ii) $\alpha<0, \alpha \otimes \tilde{A}=\left(\alpha a_{4}, \alpha a_{3}, \alpha a_{2}, \alpha a_{1}\right)$.

\section{3.}

\section{Assumptions and notations}

3.1. Assumptions: Following assumptions are made to develop the model

(1) Demand rate is constant.

(2) Deterioration is constant at the rate of $\theta$ quantities at a time

(3) Shortages are not allowed.

(4) Replenishment and production is instantaneous.

(5) The interest rate paid is same for both retailer and supplier.

(6) Time horizon is infinite.

3.2. Notations: Following notations have been used thought out the paper

d Annual demand

Q Retailer's order quantity

$\mathrm{T} \quad$ Retailer's replenishment time interval

M Credit time

$\tilde{h}$ Retailer's fuzzy holding cost per item

$\tilde{p} \quad$ Retailer's fuzzy purchase price per item

$\tilde{c} \quad$ Fuzzy deterioration cost per item

$\tilde{K} \quad$ Supplier's fuzzy setup cost

$\tilde{k} \quad$ Supplier's fuzzy production cost per item

$\tilde{I}_{e} \quad$ Fuzzy interest earned per $\$$ in a year

$\tilde{I}_{p} \quad$ Fuzzy interest paid per $\$$ investment per year

$\tilde{S} \quad$ Fuzzy cost of placing one order

\section{INVENTORY MODEL}

\subsection{Retailer's inventory model}

In this model we assume that the retailer's inventory level decreases due the constant demand and the constant deterioration also. Differential equation governing the model is as follows,

$$
I^{\prime}(t)+\theta I(t)=-d, \quad 0 \leq t \leq T
$$

With the boundary condition I $(\mathrm{T})=0$, on solving the above equation we have

$$
I(t)=\frac{d}{\theta}\left[e^{\theta(T-t)}-1\right], 0 \leq t \leq T
$$

Retailer's maximum inventory level is

$$
I_{0}=\frac{d}{\theta}\left[e^{\theta T}-1\right]
$$

Retailer's ordering cost

$$
\tilde{O} \tilde{C}=\tilde{S}
$$

Retailer's holding cost

$$
\tilde{H} \tilde{C}=\frac{\tilde{h} d}{\theta^{2}}\left[e^{\theta T}-\theta T-1\right]
$$

Retailer's deterioration cost

$$
\tilde{D} \tilde{C}=\frac{\tilde{c} d}{\theta}\left[e^{\theta T}-\theta T-1\right]
$$


Since the inventory level at time t, I(t), is known in terms of known parameters, the total cost function may be evaluated now under different prevailing situations.

Inventory Scenarios: For the fixed credit period M, there are two different scenarios such as.

(1) Payment at or before the depletion of inventory $(\mathrm{M} \leq$ $\mathrm{T})$,

(2) Payment after total depletion of inventory $(\mathrm{M}>\mathrm{T})$

\subsubsection{Case 1. $M \leq T$}

This situation is arises when the permissible trade credits time expires on or before the time inventory level becomes zero. Thus the items are sold and the interest is earned on the sales revenue. The maximum accumulated amount earning interest during the credit time equals $\mathrm{dpM}$, hence the interest earned during credit time is

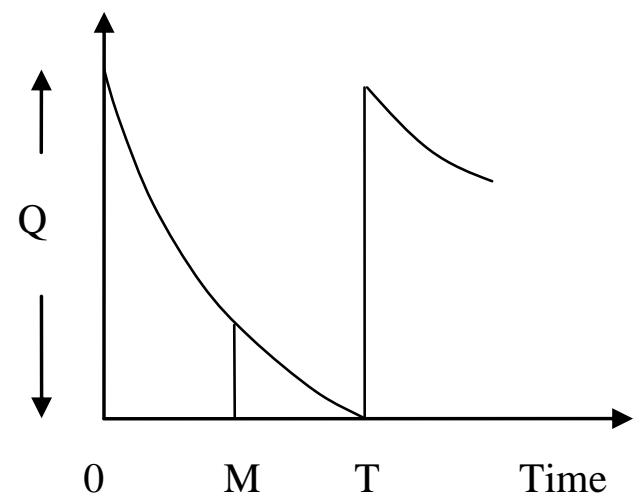

Fig 1: Retailer's Inventory Level when $M \leq T$

$\tilde{\mathrm{IE}}_{1}=\frac{\tilde{\mathrm{p}} \tilde{\mathrm{I}}_{\mathrm{e}} \mathrm{dM}}{2}$

As the account is settled, the unsolved items in stock have to be financed at interest rate $I_{p}$, hence the interest payable per cycle for the stock not being sold after the due date $\mathrm{M}$ is

$\tilde{I} \tilde{P}_{1}=\frac{\tilde{p} \tilde{I}_{p} d}{\theta^{2}}\left[e^{\theta(T-M)}-\theta(T-M)-1\right]$

Retailer's total variable cost is comprised of the sum of the ordering cost, holding cost, deterioration cost and the cost of interest payable minus the cost of interest earned.

Therefore the retailer's total cost $\tilde{T} \tilde{C}_{1}(T)$ is as follows:

$\tilde{T} \tilde{C}_{1}(T)=\tilde{H} \tilde{C}+\tilde{D} \tilde{C}+\tilde{O} \tilde{C}+\tilde{I P}-\tilde{I} \tilde{E}_{1}$

\subsubsection{Case 2. $M>T$}

In this case, the interest payable per cycle is zero, because the supplier's can be paid in full at the time M, the interest earned per cycle is the interest earned during the positive inventory period plus the interested earned from the each amount invested during time period ( $\mathrm{T}, \mathrm{M})$ after the inventory is exhausted at the time $T$, hence the interest earned during the cycle is

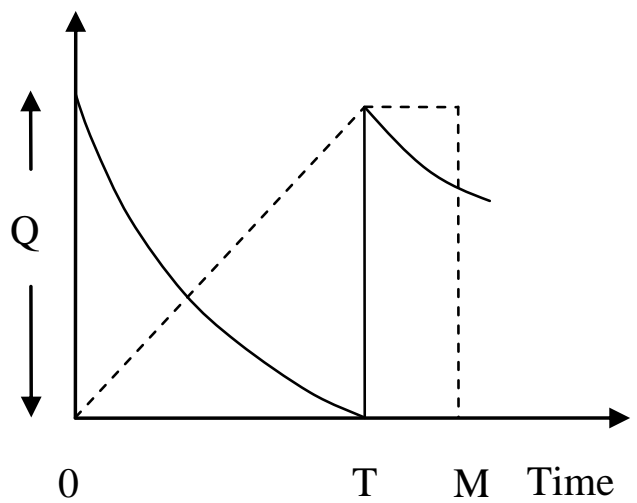

Fig 2: Retailer's Inventory Level when $M>T$

$\tilde{I} \tilde{E}_{2}=\tilde{p} \tilde{I}_{e} d T\left(M-\frac{T}{2}\right)$

Since supplier's can be paid in full at the time M', therefore interest paid will be zero. i.e.

$\tilde{I} \tilde{P}_{2}=0$

Therefore, in this case, the retailer's total cost $\tilde{T} \tilde{C}_{2}(T)$ as follow:

$\tilde{T} \tilde{C}_{2}(T)=\tilde{H} \tilde{C}+\tilde{D} \tilde{C}+\tilde{O} \tilde{C}+\tilde{I} \tilde{P}_{2}-\tilde{I} \tilde{E}_{2}$

For a given fixed $\mathrm{M}$, the problem is to decide the optimal $\mathrm{T}^{*}$ to minimize total cost function. Where

$\tilde{T} \tilde{C}_{r}(T)=\left\{\begin{array}{l}\tilde{T} \tilde{C}_{1}(T), \text { if } M \leq T, \\ \tilde{T} \tilde{C}_{2}(T), \text { if } M>T .\end{array}\right.$

\subsection{Supplier's Inventory Model}

The supplier's annual total profit consists of the following elements.

Setup cost $=\tilde{K}$

Total interest payable

$\tilde{\mathrm{IP}} \tilde{\mathrm{N}}_{s}=\tilde{\mathrm{k}} \tilde{\mathrm{I}}_{\mathrm{p}} \mathrm{dM}$

Therefore supplier's total cost per unit time $\tilde{T} \tilde{C}_{s}(T)$ is as follows:

$\tilde{T} \tilde{C}_{s}(T)=\tilde{K}+\tilde{k} \tilde{I}_{p} d T M$

The integrated total cost of the supplier and the retailer is

$\tilde{T} \tilde{C}(T)=\tilde{T} \tilde{C}_{r}(T)+\tilde{T} \tilde{C}_{s}(T)$

\section{NUMERICAL EXAMPLE}

the following data have used to find the illustrate the model, Given $\mathrm{d}=400$ units/year, $\theta=0.01$, $\tilde{h}=[(0.54,0.60,0.64: 0.6),(0.50,0.60,0.68: 1)]$

$\tilde{I}_{p}=[(0.34,0.40,0.44: 0.6),(0.30,0.40,0.48: 1)]$

$\tilde{I}_{e}=[(0.04,0.10,0.14: 0.6),(0.02,0.10,0.16: 1)]$

$\tilde{S}=[(440,500,540: 0.6),(400,500,560: 1)]$ 
$\tilde{c}=[(0.74,0.80,0.84: 0.6),(0.70,0.80,0.88: 1)]$

$\tilde{k}=[(54,60,64: 0.6),(50,60,68: 1)]$

$\tilde{p}=[(94,100,104: 0.6),(90,100,108: 1)]$

$\tilde{K}=[(184,200,214: 0.6),(180,200,218: 1)]$

Optimal solutions are obtained from equation (17) using the Mathematica 7.0, results are presented the table 1, with different credit time as shown below:

\section{OBSERVATIONS}

1. From tables, we see that the integrated cost policy results in an impressive cost reduction as compared to the individuals cost policies.

2. From tables, it is clear that the retailer's cost increases in the integrated cost policy as compared to the individual cost policy.

3. It is also observed that the supplier's cost decreases in the integrated cost policy as compared to the individual cost policy.

4. From table it is seen as the value of $M$ increases, the retailer's cost decreases, it is justifiable as the credit period time increases retailer can earn more interest on the sold items and can generate more revenues.

5. From table it is clear that after a certain credit period, retailer's total cost becomes negative, it may be possible because as the credit period increases he earns more interest on the sold items.

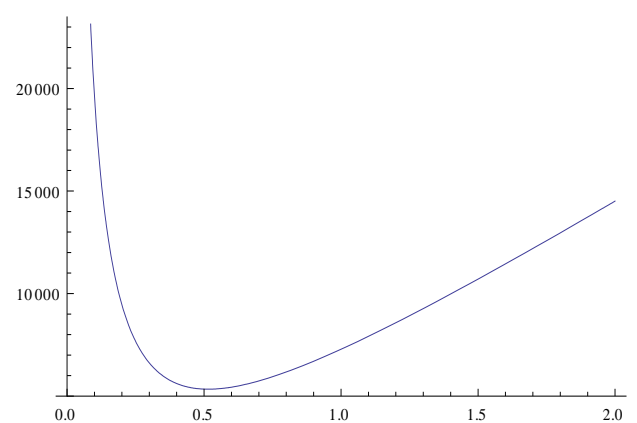

Fig 3: Graphical representation of Total cost w.r.t. time

\section{CONCLUSIONS}

In this paper, we study a supply chain consisting of a retailer and a supplier who permits a trade credit period in payment to retailer in fuzzy environment for the deteriorating items. In the development of the inventory model, most of the researchers considered that the cost of holding the inventory, deteriorating cost, rate of interest earned/paid are fixed or constant throughout the time. But in realistic and in market oriented situations these quantities are not exactly constant, but have a little disturbances from the actual values. So for more matching the target to study in the realistic situations, we developed the model considering these quantities as the fuzzy in nature. These quantities are taken as triangular fuzzy number and the total cost is represented by a level $(\lambda, 1)$ Interval-Valued Fuzzy Number. Total cost is defuzzified by using the Signed Distance Method. In this paper, we used the integrated cost policy instead of the individual cost policy for the buyers and the supplier. Mathematica 7.0 is being used to find the optimal policies. At last we compared the integrated cost policy with the individual cost policy, and shows that the integrated cost policy results in an impressive cost reduction as compared to the individual cost policy. Although retailer is a looser in the integrated cost policy, and supplier is a gainer. But the supplier's gain is more than the retailer's lose. Therefore in order to convince the retailer for the integrated cost policy, supplier may give some sort of quantity discount to the retailer, in order to make the integrated cost policy a win-win situation for both the retailer and the supplier.

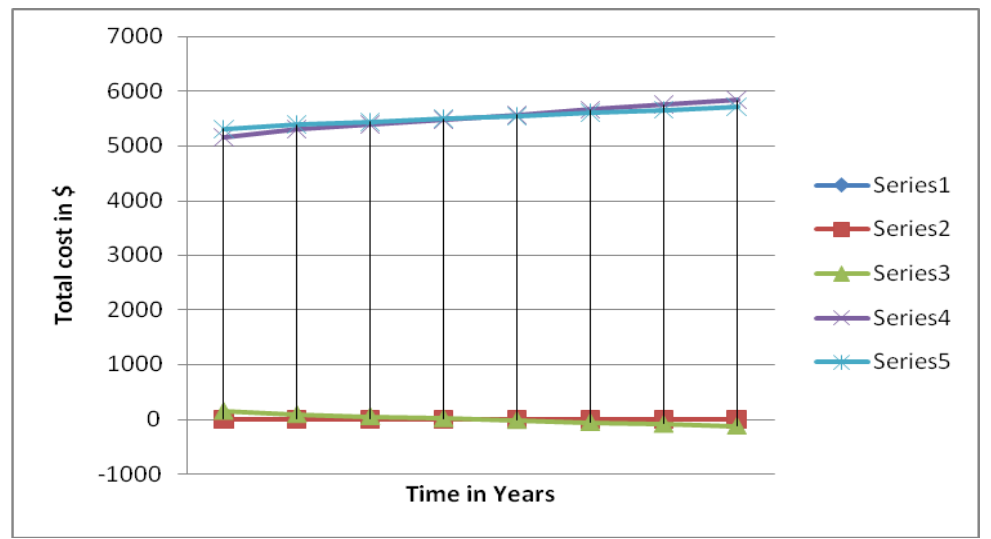

Fig 4: Graphical representations of various cost with credit time

Table 1: Integrated Cost Policy

\begin{tabular}{ccccc}
\hline $\begin{array}{c}\text { Credit Time M } \\
\text { (years) }\end{array}$ & $T^{*}$ (years) & $\begin{array}{c}\text { Retailer's } \\
\text { Cost }(\$)\end{array}$ & $\begin{array}{c}\text { Supplier’s } \\
\text { Cost }(\$)\end{array}$ & $\begin{array}{c}\text { Supply chain } \\
\text { Cost }(\$)\end{array}$ \\
\hline 0.500 & 0.516 & 157.10 & 5139.60 & 5296.70 \\
\hline 0.516 & 0.527 & 96.78 & 5283.57 & 5380.35 \\
\hline 0.526 & 0.534 & 59.90 & 5373.64 & 5433.53 \\
\hline 0.536 & 0.541 & 23.56 & 5463.83 & 5487.38 \\
\hline
\end{tabular}




\begin{tabular}{lllll}
\hline 0.546 & 0.548 & -12.26 & 5548.90 & 5554.15 \\
\hline 0.556 & 0.556 & -46.96 & 5643.94 & 5596.97 \\
\hline 0.566 & 0.563 & -81.84 & 5734.50 & 5652.66 \\
\hline 0.576 & 0.570 & -116.25 & 5825.18 & 5708.91 \\
\hline
\end{tabular}

Table 2: Individual Cost Policy

\begin{tabular}{ccccc}
\hline $\begin{array}{c}\text { Credit Time M } \\
\text { (years) }\end{array}$ & $T^{*}$ (years) & $\begin{array}{c}\text { Retailer's } \\
\text { Cost }(\$)\end{array}$ & $\begin{array}{c}\text { Supplier's } \\
\text { Cost }(\$)\end{array}$ & $\begin{array}{c}\text { Supply chain } \\
\text { Cost }(\$)\end{array}$ \\
\hline 0.500 & 0.492 & 147.99 & 5158.50 & 5305.50 \\
\hline 0.516 & 0.503 & 88.46 & 5301.05 & 5389.51 \\
\hline 0.526 & 0.511 & 52.00 & 5390.49 & 5442.49 \\
\hline 0.536 & 0.518 & 16.08 & 5480.24 & 5496.32 \\
\hline 0.546 & 0.526 & -19.32 & 5569.41 & 5550.09 \\
\hline 0.556 & 0.533 & -54.22 & 5659.46 & 5605.24 \\
\hline 0.566 & 0.541 & -88.65 & 5748.95 & 5660.30 \\
\hline 0.576 & 0.548 & -122.62 & 5839.27 & 5716.65 \\
\hline
\end{tabular}

\section{REFERENCES}

[1] Aviv, Y., 2001. 'The effect of collaborative forecasting on supply chain performance', Management Science, Vol. 47, No. 10, pp. 1326-1343.

[2] Chang H.C., Yao J.S., Quyang L.Y., 2004. Fuzzy mixture inventory model with variable lead-time based on probabilistic fuzzy set and triangular fuzzy number. Computer and Mathematical Modeling, 39, 287-304.

[3] Chang, Tao C., Ouyang, Yuh L., Teng, Tsair J., 2003. An EOQ model for deteriorating items under supplier credits linked to ordering quantity. Applied Mathematics Modeling, 27(12), 983-996.

[4] Chen L.H., Kang F.S., 2007. Integrated vendor-buyer cooperative inventory models with variant permissible delay in payments. European Journal of Operational Research, 183(2), 933-943.

[5] Goyal S.K., 1985. Economic order quantity under conditions of permissible delay in payments. The Journal of the Operational Research Society, 36 (4), 335-338.

[6] Hwang H., Shinn S.W., 1997. Retailer's pricing and lot sizing policy for exponentially deteriorating product under condition of permissible delay in payments. Computer and Operations Research, 24, 539-547.

[7] Kim S.W., Park S., 2008. Development of a threeechelon SC model to optimize coordination costs. European Journal of Operational Research, 184(3), 10441061.

[8] Maloni, M.J., Benton, W.C., 1997. Supply chain partnership: opportunities for operations research, European Journal of Operational Research, 101, 419-429.

[9] Rau H., Ouyang B.C., 2008. An optimal batch size for integrated production-inventory policy in a supply chain. European Journal of Operational Research, 185(2); 619634.

[10] Singh S.R., Singh T.J., Singh C., 2007. Perishable inventory model with quadratic demand, partial backlogging and permissible delay in payments International Review of Pure and Applied Mathematics, 3(2), 199-212.

[11] Singh, S.R. and Singh, C., 2008. Fuzzy inventory model for finite rate of replenishment using signed distance method, International Transactions in Mathematical Sciences and Computer, 1(1), 21-30.

[12] Singh, S. R., Singh, C., 2010. Two echelon supply chain model with imperfect production, for Weibull distribution deteriorating items under imprecise and inflationary environment. International Journal of Operations Research and Optimization, 1(1), 9-25.

[13] Singh, S. R., Singh, C., 2010. Supply Chain Model with Stochastic Lead Time under Imprecise Partially Backlogging and Fuzzy Ramp-Type Demand for Expiring Items. International Journal of Operational Research, 8(4), 511-522.

[14] Thomas, D.J., Grif.n, P.M., 1996. Coordinated supply chain management. European Journal of Operational Research, 94, 1-15.

[15] Wu Z., Choi T.Y., 2005. Supplier-supplier relationships in the buyer-supplier triad: Building theories from eight case studies. Journal of Operations Management, 24(5), $27-52$.

[16] Yang P.C., Wee H.M., 2000. Economic order policy of deteriorated items for vendor and buyer: An integral approach. Production Planning and Control Management, 16(6), 455-463.

[17] Yao J.S., Lee H.M., 1999. Fuzzy inventory with or without backorder for fuzzy order quantity with trapezoidal fuzzy number. Fuzzy Sets and Systems, 105, 311-337.

[18] Yao J.S., Chang S.C., Su J.S., 2000. Fuzzy inventory without backorder for fuzzy order quantity and fuzzy total demand quantity. European Journal of Operational Research, 148, 401-409. 